\title{
Research on the fuel consumption conservation potential of ADAS on passenger cars
}

\author{
Guogang Qian*, Tieqiang Fu, and Long Sun \\ China Automotive technology and research center Co. Ltd, Tianjin, PR.China
}

\begin{abstract}
Keywords: advanced driver assistance systems, connected autonomous vehicles, fuel consumption, passenger cars.

Abstract. Under the trend of automobile electrification, network connection, and intelligence, EU and USA have carried out fuel-saving research and initiatives on ADAS and CAV. The eCoMove project has aimed at economically optimal driving control and traffic management; MAVEN discusses the technical path of GLOSA (Green Light Optimal Speed Advisory) and ecological auto-driving EAD (Eco-Autonomous Driving) by smoothing the vehicle speed. The American NEXTCAR project contains multiple projects. When supplemented with DSF (Dynamic Skip Fire) and 48V technology, the road test led by Ohio State University resulted in a $15 \%$ fuel saving rate. Platoon and optimizing intersection signal lights can offer vehicles a more fuel-efficient condition; slope energy utilization, HEV SOC active management, cold storage evaporator, coasting, $48 \mathrm{~V}$ and mDSF (miller cycle Dynamic Skip Fire) fuel-saving potential has been fully utilized.
\end{abstract}

\section{Preface}

Advanced Driver-Assistance System (ADAS) and Connected and Autonomous Vehicles (CAV) can not only refrain the driver from fatigue and avoid traffic accidents, but also achieve energy saving and fuel conservation. In recent years, ADAS and CAV are developing rapidly in energy efficiency of vehicles ${ }^{[1]}$. ADAS was initialed by the Advanced Driver-Assistance System Interface Specifications Forum (ADASIS Forum), which is established in Europe in May 2001; the second edition released in 2012, with the merit of data format simplification, expendability, and the availability of software module for protocol testing, was extensively accepted around the OEMs. Version 3 is the latest version of ADAS.

Many advanced exploration projects were carried out by USA on ADAS, such as Safety Pilot Model Deployment 2011 project, the study cooperated by UMTRI (University of Michigan Transportation Research Institute) and Ann Arbor city ${ }^{[2]}$. UMTRI also leads another improving energy efficiency project in year $2015^{[3]}$ succeeding that cooperation.

\footnotetext{
* Corresponding author: qianguogang@catarc.ac.cn
} 


\section{Researches and activities in EU}

Many research projects on ADAS/CAV' fuel efficiency were carried out in EU, such as eCoMove, Eco-innovation, Horizon 2020L3 Pilot, and Horizon Europe project for the mid-term prospect.

\section{1 eCoMove-Researches before year 2014 in Europe}

Focusing on the optimal fuel consuming control, 32 European Union units formed an alliance to run the eCoMove project in year $2010^{[4]}$, and the structure is shown in Figure 1. "V2C" means " from vehicle to traffic management center", "V2I" means " from vehicle to infrastructure", "V2V" means " from vehicle to vehicle".

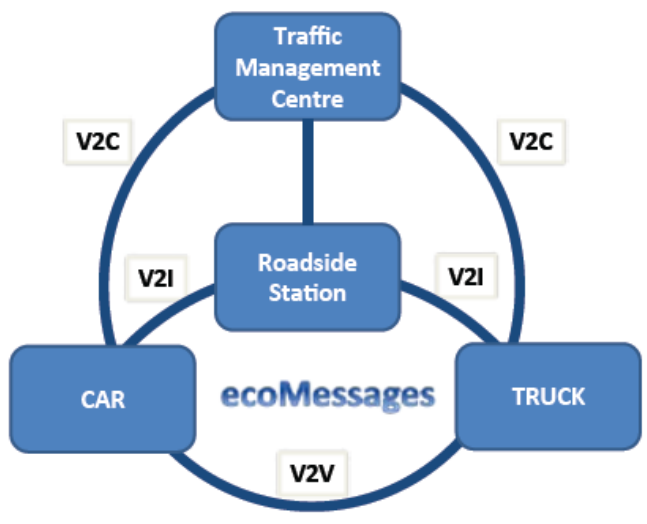

Fig. 1. eCoMove system's information flow.

eCoMove analyzes the typical factors that increase fuel consumption, including traffic congestion, non-optimal routes, unavailable of traffic control arrangement from the government to individual cars, and aggressive driving. It is beneficial to assist drivers picking up an optimal route and behavioring a driving with more fuel-efficient by dint of real time information. Fuel-saving strategies include traffic light control optimization, deserting the improper driving habit, navigation, parking guidance, and highway management optimization. The fuel-saving rate generally about $4 \%$ to $25 \%$, and typically $12 \%$ when the road traffic is heavy. An ecological platform named "eco Horizon" is shown in Figure 2, which includes a real time ecological perspective in information transferring, maps, navigation, collaboration platforms, status models, strategy models, and human-machine interfaces. 


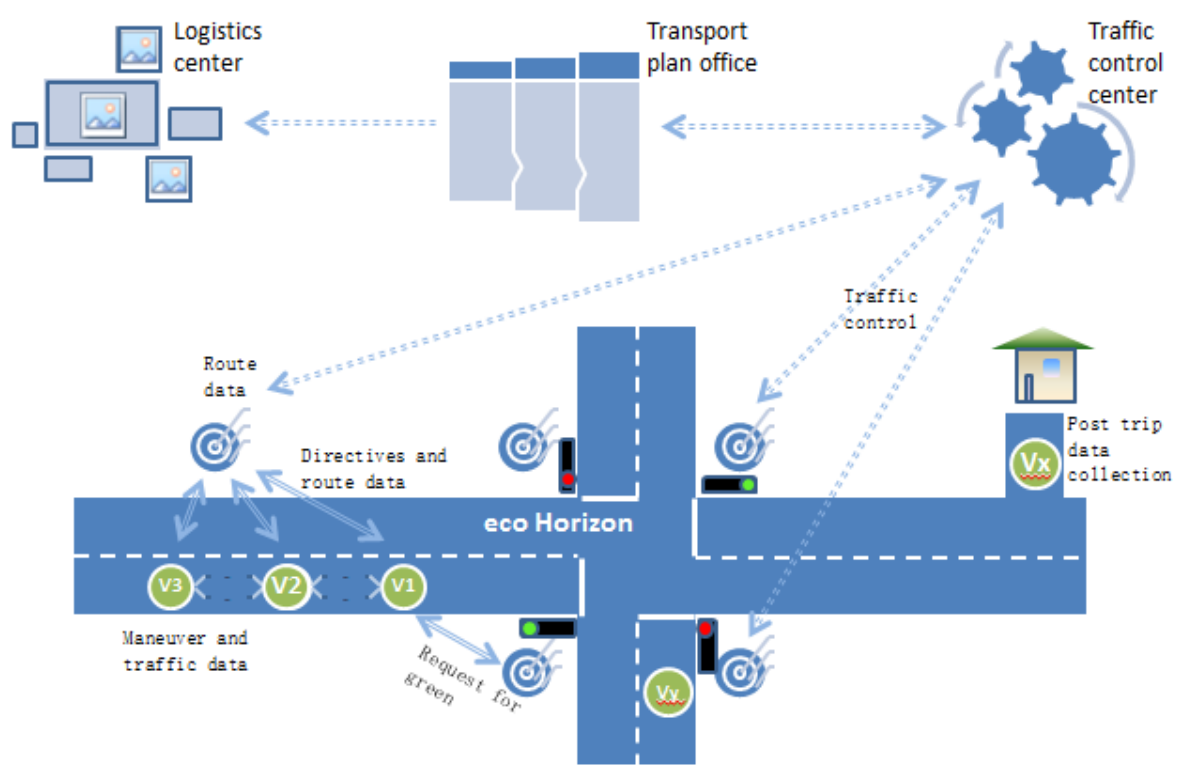

Fig. 2. eco Horizon chart flow.

V2X (from the vehicle to the outside world) technology is a prerequisite for eCoMove applications. When most of the vehicles in the traffic are equipped with V2X, the ecological platform can appropriately extend the green light to release more vehicles or fleets when applicable, so as to improve overall traffic efficiency. The I2V (from infrastructure to the vehicle) information also offers more flexibility for traffic control. While not only the traffic light switching plan is acquirable, but also the speed and lane information of the vehicles in vicinity is transparent to a vehicle, it can calculate a recommended speed by ADAS.

\subsection{Horizon subject-Research in EU after 2014}

\subsubsection{AdaptiVe project}

AdaptiVe project analyzes the needs of drivers, legislative environment in EU, and the test procedure for evaluation. Level 1 to 4 is defined in AdaptiVe.

\subsubsection{MAVEN Project's progress in V2X}

Unlike prior I2V (infrastructure to vehicle) single-direction communication, MAVEN (Managing Automated Vehicles Enhances Network) has been upgraded to twin-direction interaction. With the support of network and satellite transmission technology, synthesis with local dynamic map (LDM), CAV vehicles can reliably interact with a wide range of infrastructure systems, especially at signalized intersections which locates in the urban areas with narrow streets, so as to achieve CACC (Cooperative Adaptive Cruise Control) function.

Combining V2I (sending from vehicles to external facilities) and V2V (sending from vehicles to vehicles), MAVEN can simulate GLOSA (Green Light Optimal Speed Advisory) technology. A EAD (Eco-Autonomous Driving) module is embedded in the model, which can smooth the speed by minimizing abnormal acceleration and deceleration. Under the US 
EPA's 5 cycle tests, the fuel economy can be optimized by 3\%.A greater benefit can be reached in the Austin cycle, which is 6.55\%. Generated from Austin's 2006 vehicle speed on road sampling species, the Austin cycle consists of an urban part and a suburban $\operatorname{part}^{[5]}$.

Another example of smooth is done by The University of Texas at Austin. Their model complies an EAD process (Eco-Autonomous Driving) by "spline data interpolation (spline)" method, with a presumption that the driving mileage unchanged. The solution is the output which can minimize the output of formula (1). The value of the smoothing factor

$\lambda$ represents the intense of the smoothness to the original curve: When $\lambda$ is 0 , the curve remains unchanged; when $\lambda$ tends to be $+\infty$, the curve is simplified to a linear line. $\lambda$ is assigned 0.23 in their research ${ }^{[6]}$. For example, the PKE (Positive Kinetic Energy, positive acceleration energy per unit distance) of SC03 cycle conditions is $20 \%$ higher than the value of UDDS's $0 \sim 505 \mathrm{~s}$ section ${ }^{[7]}$, and it will be altered more dramatically through EAD smoothing than UDDS's section.

$$
\begin{aligned}
\arg \min _{m}=\frac{1}{n} \sum_{i=1}^{n}\left(y_{i}-m\left(x_{i}\right)\right)^{2} \\
+\lambda \int d x\left(m^{\prime \prime}(x)\right)^{2}
\end{aligned}
$$

The first term in the formula is "mean square error(MSE)", $y_{i}$ is the value of $y$ at $i^{\text {th }}$ data point $\mathrm{x}_{\mathrm{i}}$ in the original driving cycle, $\mathrm{i}=1,2, \ldots, \mathrm{n}$; and $\mathrm{m}\left(\mathrm{x}_{\mathrm{i}}\right)$ is the predicted value of $\mathrm{m}$ at the $\mathrm{i}^{\text {th }}$ data point $\mathrm{x}_{\mathrm{i}}$ in the smoothed cycle. $\lambda$ is smoothness factor to penalize MSEs.

\subsubsection{L3 Pilot}

The L3 Pilot project inherits the research results of AdaptiVe, and further focuses on how autonomous vehicles can be effectively integrated into European transportation infrastructure ${ }^{[8]}$. The project is constructed by 36 institutes, 100 self-driving cars, and 1,000 drivers. It was launched in 11 countries in Europe. The large-scale trial of L3 level functions was operated in 2017-2021, and some L4 level functions were evaluated. L3 Pilot has developed practical guidelines that describe the typical process of designing and developing autonomous driving functions, including checklists and the operation methods for functional safety confirmation.

\subsubsection{Horizon's further action}

In June 2018, the European Commission released the Horizon Europe project, which proposed a blueprint for research and innovation from 2021 to 2027. Over 1/6 of the funds were invested in climate, energy and transportation.

\subsection{Eco-innovation in EU}

For a technology to be approved as an Eco-innovation, there are 7 criterions deems to comply ${ }^{[9]}$ : the conditions are innovative, basic (except for occupant comfort), verifiability, measurability, not reflected or insufficient in traditional test methods Reflects $\mathrm{CO} 2$ reduction capability, penetration rate is less than 3\%, and "not covered by Article 2 (1) of Regulation (EU) No725 / 2011". The EU has approved 26 items and granted them $\mathrm{CO}_{2}$ emission discounts, among whom are Bosch's two issues relating to ADAS ${ }^{[10],[11]}$. 


\section{Researches and activities in US}

Among all the 7 sub-fields in ARPA-E (Advanced Research Projects Agency-Energy) program in USA, NEXTCAR (Next-Generation Energy Technologies for Connected and Automated on Road Vehicles, CAV next-generation energy technology) ${ }^{[12]}$ has granted about 10 projects.

Quite some output of the NEXTCAR project can be found in SAE literatures in 2019: General Motors focuses on vehicle and traffic environment simulation ${ }^{[13]}$. PSU (Pennsylvania State University) has analyzed the platoon of heavy-duty vehicles without jeopardizing the air cooling of the engine ${ }^{[14]}$, MTU (Michigan Technology University) carried out the simulation and tests for the vehicles in running cycles ${ }^{[15]}$, SwRI (Southwest Research Institute) explored and practiced the bench test method ${ }^{[16]}$. OSU (Ohio State University) concerns the potential of various fuel-saving technologies ${ }^{[17]}$.

In 2018, OSU announced two research results, one is of the performance improvement of coasting in $\mathrm{N}$ gear ${ }^{[18]}$, and the other is about the nonlinear simulation of predictive cruise control ${ }^{[19]}$. By modifying 2010 Prius, CSU(Colorado State University) inquired several research topics, including the speed prediction by V2V-based technology vehicle to improve HEV fuel economy ${ }^{[20]}$, ADAS to improve vehicle fuel economy ${ }^{[21]}$, and improve the accuracy of prediction on fuel economy by control optimize ${ }^{[22]}$.

\section{Analysis of the fuel conservation potential}

\subsection{Platoon and the optimization of traffic signals for intersections}

The distance between the vehicles is shortened when they are in platoon, so that the air resistance of the subsequent vehicles can be reduced. Great divergence about the fuel-saving rate appears among different publications, yet many institutes agrees the effect is promising when applied on commercial vehicles.

PSU believes that platoon technology saves $2.5 \%$ fuel in the Composite Highway cycle while taking into account the cooling air required for the thermal management of the vehicle engine ${ }^{[14]}$, which is about $2.4 \mathrm{~h}$.

The Cambridge University study ${ }^{[23]}$ believes a more optimistic fuel economy expectation of $7 \%$ is achievable.

As a group of several cars, platoon will generally been offered more priorities to pass through directly when crossing the intersections supporting CAV. As each car can benefit from this concern, the gain in fuel saving will be multiplied. The MAVEN project uses SUMO software to simulate the urban driving of passenger cars, and a plug-in for simulating the green wave of the platoon is built in SUMO to support this function, which names simpa.

CACC (Cooperative Adaptive Cruise Control) coordinates the traffic control and the vehicle's internal system to ensure that the vehicle's power system works as often as possible in the high-efficiency range, while arriving the destination in time.

There several methods to smooth the speed, such as the spline smooth method by the University of Texas at Austin and SwRI's CAV-PT method. A 2\% fuel saving rate under the US06 cycle is achieved in the second method by a revised 2017 PHEV Prius Prime ${ }^{[16]}$.

Quite a part of fuel is consumed while the vehicle wandering around for a parking slot in urban area, and during the creeps procedure to adjust the vehicle to a gesture that is kind to cars in vicinity. The fuel wasted is estimated to be $30 \%$ in MIT research, and ADAS's parking guidance and active parking technology can effectively reduce the amount. 


\subsection{Road slope energy}

Potential energy is available when the slope of the road is not minor. In 2013, An eco-innovation about navigation-based HEV SOC preconditioning technology was authorized to Bosch company ${ }^{[10]}$, in which the slope is also taken into account.

The $\mathrm{CO}_{2}$ emission credit is generated as formula(2), and a chassis dyno test system which can simulate slope resistance is necessary to accomplish the test. When measuring the fuel consumption of eco-innovation, a resistance load to the vehicle according to the real-time vehicle speed and road slope curve shown in Figure 3 is applied on the chassis dyno. Simulated GPS data and slope data stream is transferred to the vehicle's GPS information portal in real time, by the external storage device, so as to provide the overall environment condition to the vehicle to perform ADAS control.

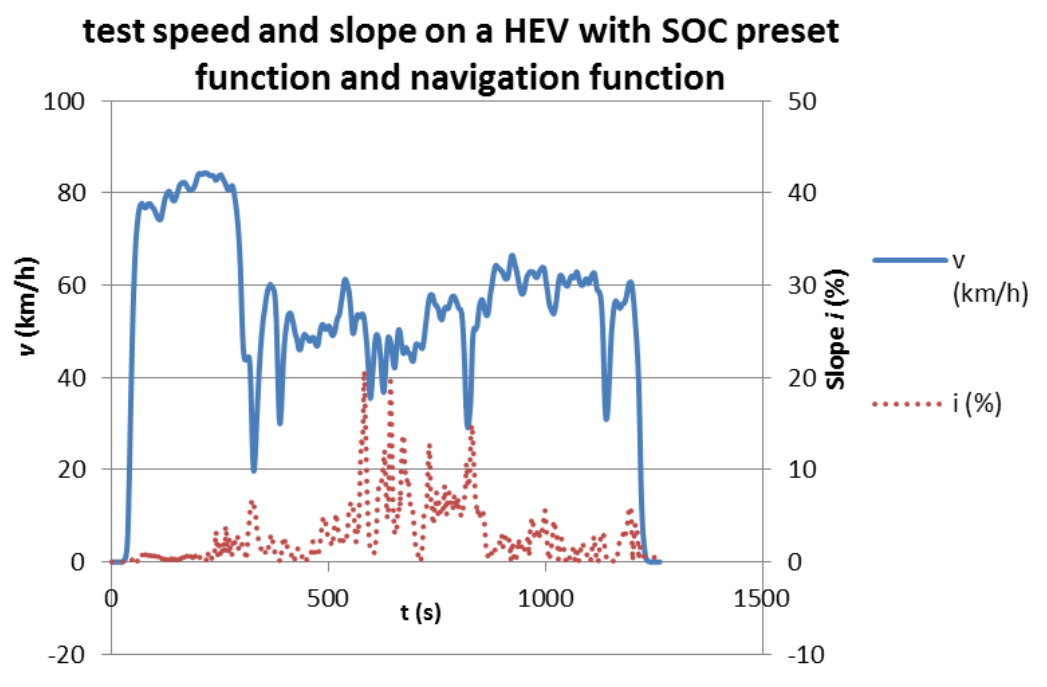

Fig. 3. Test speed and slope on a HEV with SOC preset function and navigation function.

$$
\mathrm{C}_{\mathrm{CO}_{2}}=\left(B_{\mathrm{MC}}-E_{M C}\right) \times U F
$$

Here, Parameter $B_{M C}$ is the $\mathrm{CO}_{2}$ emission under the test procedure for the benchmark vehicle, and $E_{M C}$ is the $\mathrm{CO}_{2}$ emission of the eco-innovation vehicle in the test with adjusted speed curve, $U F$ is the utilization factor, which is 0.15 .

In order to avoid running the engine for cooling purposes during the downhill process, the air-conditioning system can be set to enhance cooling before the vehicle reaches the top of the slope, so as to make the temperature in the cabin reduce a bit further.

An advanced algorithm that consists slope information processing, named ANLMPC (Adaptive Nonlinear Model Predictive Controller), is adopted by OSU. A further Fuel saving $4.33 \%$ is achieved by this algorithm in a typical test road, since the gear shift operation of the vehicle was reduced to 38 , a far cry from the number which occurs in the CACC control, which is $90^{[19]}$.

\subsection{SOC management of PHEV}

Two tests launched on PHEV Volt II by MTU, names run5 and run6, are representive to illustrate the merit of SOC management on PHEVs with the aid of CAV. these two tests were conducted on the same road section of $38.3 \mathrm{~km}$ mileage. The maximum speed is 
about $90 \mathrm{~km} / \mathrm{h}$, which is mainly acquired in the beginning and end periods of the trip, while the speed in the middle period is generally below $50 \mathrm{~km} / \mathrm{h}$ speed. Details are shown in Table 1. Comparing to run6, The initial SOC of run5 possesses $1.84 \mathrm{kWh}$ more energy. However, the total energy consumption value of run 6 is merely $0.84 \mathrm{kWh}$ more than $\operatorname{run} 5^{[15]}$, and the comparing evidences that PHEV's energy consumption can be reduced $1 \mathrm{kWh}$ by ADAS/CAV-based predictive fuel-saving driving plus lightweight.

Table 1. Run5 test and run6 test on PHEV Volt II

\begin{tabular}{l|c|c}
\hline \multicolumn{1}{c|}{ Test setting } & run5 & run6 \\
\hline SOC initial & $25 \%$ & $15 \%$ \\
\hline Added ballast(kg) & 330 & 0 \\
\hline Aggressive drive & $\sqrt{ }$ \\
\hline Gentle accelerator input & $\times$ & $\sqrt{ }$ \\
\hline Coasting & $\times$ & $\sqrt{ }$ \\
\hline Early braking & $\times$ & $\sqrt{ }$ \\
\hline Regenerative braking paddle & $\begin{array}{c}\text { About 15km } \\
\text { mileage }\end{array}$ & At beginning \\
\hline CS mode start at &
\end{tabular}

When real time $\mathrm{V} 2 \mathrm{~V}$ communication and the previous driving records database are available, HEV energy management can be optimized by speed prediction. CSU (California State University) research reports that a NOVC 2010 Prius can save up to $6 \%$ fuel after taking into account of the forecast period interval and fidelity ${ }^{[20]}$.

Tsinghua University apply adaptive energy management strategies to PHEV buses which utilizing synthesis traffic information. By contrast, the new strategy can save fuel by up to $15 \%{ }^{[24]}$ comparing to the traditional CDCS (Charge-Depleting followed by Charge-Sustaining). The curves of SOC under the two strategies is shown in Figure 4.

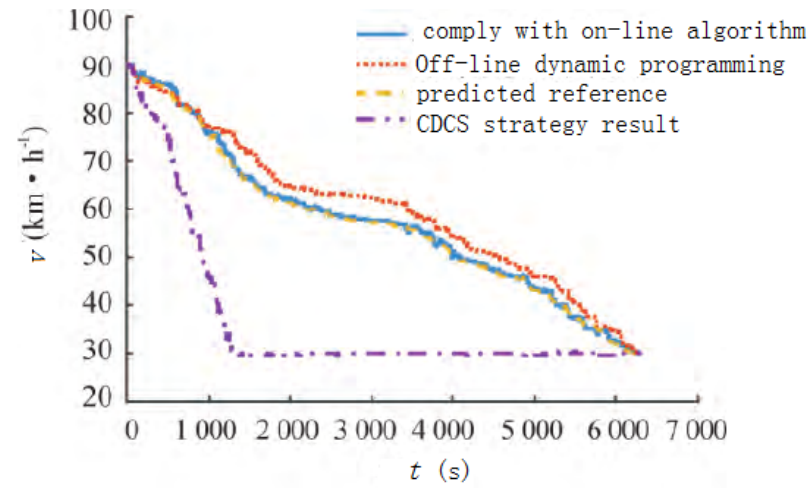

Fig. 4. The SOC in the two strategies on a PHEV bus.

Hyundai Motor Company proposed an EDPS (energy-optimal deceleration planning system) to maximize regenerative energy for PHEV on deceleration events, which maximize energy recuperation and avoid front collision and jittering. Their experiments on a Hyundai Ioniq PHEV's real-world driving data with CAV's EDPS strategy indicate that the regenerative energy is improved about $33 \%$ comparing to the event driven by a human driver $^{[25]}$. More regenerative energy is of contribution to the vehicle's fuel economy. 


\subsection{V and a DSF}

The fuel economy of a vehicle relies on the control synthesize effect of its relevant components. The $48 \mathrm{~V}$ electrical architecture has better power performance and response than the $12 \mathrm{~V}$ system, as more electrical components are operated by wire.

ADAS/CAV provides scheduled control signals to make electrical components ready for adjustment several seconds prior of the event. Low-speed electric crawling, electric boost acceleration, braking energy recovery, active suspension reduction, active intake grille active adjustment, coasting and other technologies, which is supported on $48 \mathrm{~V}$ Architecture, can be offered more operation opportunity.

Stop-start function, which is endowed with more flexibility by $48 \mathrm{~V}$, is expected to avoid restarting the engine after a very short time period, which may consume more fuel than keeping it running. By leveraging CAV communication through the location information obtained to enhance the awareness of surrounding traffic conditions, the governor logic for controlling can deactivate the stop-start function automatically when vehicle is in the traffic situation where it is undesired.

a DSF ( $\alpha$ Dynamic Skip Fire) cylinder deactivation technology enables each cylinder being controlled independently. For example, for a 4-cylinder machine, $\alpha \mathrm{DSF}$ can arrange all 4 cylinders to work meantime, or only 0 to 3 cylinders to generate the propelling power [26]; mDSF (miller Dynamic Skip Fire) is an additional approach for each cylinder to run at a certain low power. During the mDSF 4-cylinder engine crankshaft's rotating phase through $720 /{ }^{\circ} \mathrm{CA}$, the arrangement combination possibility has possibility.

By radar and other sensing devices and X2V, a DSF can obtain real-time CAV information, including vehicle position, traffic flow, slope, terrain, obstacles, traffic lights, etc. engine output torque command expected value can be generated based on those signals, and a cylinder working status command generated, which emphasis on fuel economy priority.

A speed curve can be adjusted by ADAS / CAV which utilizing DSF to get more constant speed periods, as shown in Figure 5.

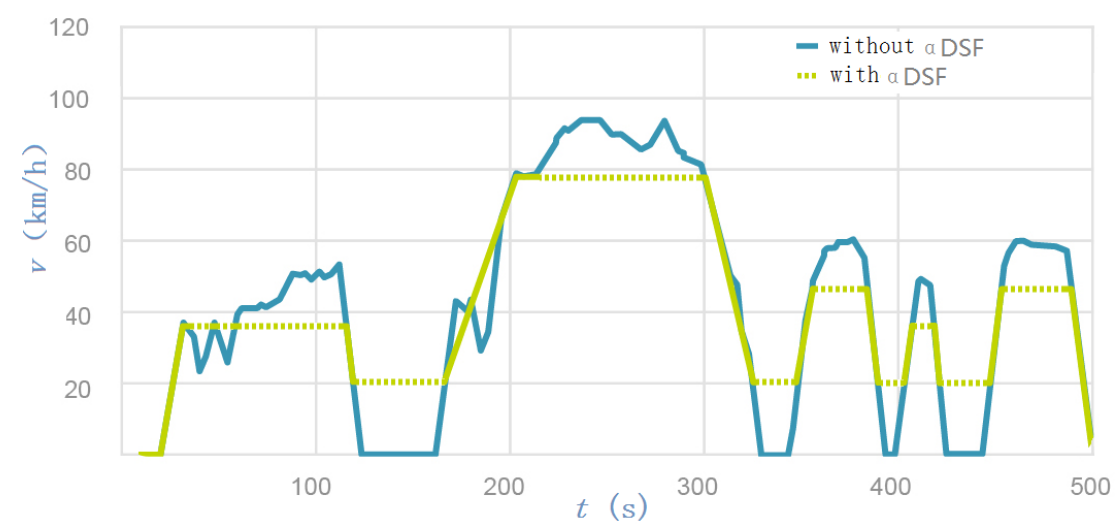

Fig.5. The speed under a DSF .vs. the speed under traditional control.

It's reported in OSU and Delphi's SAE paper that $15 \%$ fuel savings in road tests is achievable through the joint optimization by ADAS's velocity profile, DSF and powertrain torque split of $48 \mathrm{~V}$ mild hybrid technologies, while the extrinsic factors includes signal phase information for CAVs, which is derived from route characteristics and traffic conditions. 


\subsection{Coasting with $\mathbf{N}$ gear}

When the vehicle is decelerating gently, the Choices to conserve fuel includes Coasting with fuel-cut with D gear, engine idle with $\mathrm{N}$ gear, and fuel-cut with $\mathrm{N}$ gear. Drag effects from the engine's pump air loss can be eliminated in the third option, and A certain model of Mercedes-Benz in market is able to perform this function. The $48 \mathrm{~V}$ motor can be of assistance to recover braking energy and meanwhile provide additional braking force.

Certain technology risk, such as the lag of power when re-accelerating is ordered while the vehicle is coasting, has to be conquered by proper technical solutions. Besides modifying the clutch control, another advanced and effective solution is to rely on ADAS/CAV to judge the authenticity of seeming opportunities, to forecast the appropriate operating step, and to stir the control schedule accordingly .

In 2018, Bosch company announced an eco-innovation of engine idling technology ${ }^{[11]}$, together with 13 vehicle manufacturers in Europe, Japan, the United States, and South Korea. Since the engine pump air loss is eliminated from the driving resistance, fuel saving is achieved. In the NEDC cycle test, the vehicle can be driven according to the modified curve (mNEDC) shown in Figure6. "m" means "modified" .

The $\mathrm{CO}_{2}$ credit is calculated by formula (3). The utilization factor, parameter UF in formula (3), is dependent on vehicle transmission type and ADAS. For example, the coefficient for automatic transmission $\mathrm{UF}_{\mathrm{MC} \_ \text {automatic transmission }}$ is assigned 0.52 , greater than

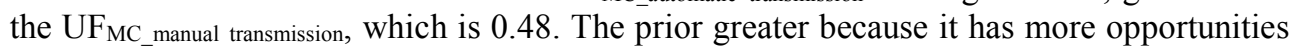
to coast.

Similarly, information such as traffic light information, surrounding traffic participant information, and road slope can also help improve UF.

$$
\mathrm{C}_{\mathrm{CO}_{2}}=\left(c \times B_{\mathrm{TAhot}}-E_{\mathrm{MC}}\right) \times U F
$$

Here, $c$ is the conversion coefficient, and the value is $0.96 ; B_{T A}$ hot is the fuel consumption value of the vehicle under the hot start of the type test (NEDC); $E_{M C}$ is the fuel consumption value of the vehicle for the ecological innovation in the speed curve test adjustment.

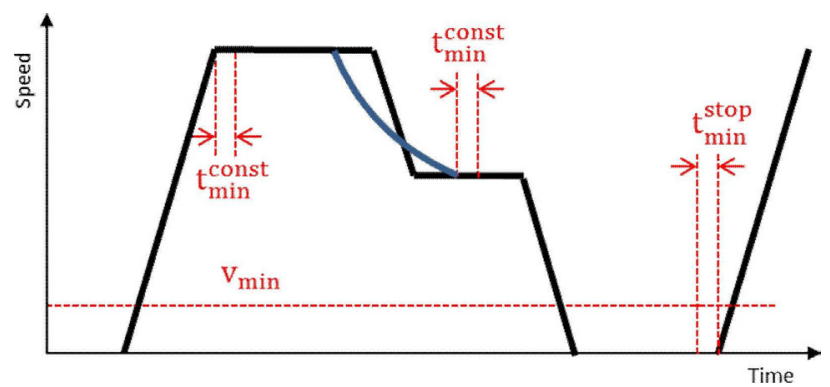

Fig. 6. mNEDC driving trace in coasting function of Bosch company.

When the road traffic ahead the vehicle is occupied by several cars, the decelerate distance and time period will be limited before a strong brake, so as an idle coasting in $\mathrm{N}$ gear will be restrain, and consequently the kinetic energy of the vehicle cannot be utilized as thoroughly as the coasting in D gear with engine fuel cut-off. An example of the instant engine rotate speed of the two kinds of control strategies during a certain gentle deceleration process are shown in Figure 7, together with the fuel injection rate of them, respective.

The vehicle decelerates from a speed of $60 \mathrm{~km} / \mathrm{h}$, and neither of two strategies injects fuel at first. Later, when the engine speed drops to the engine wake-up speed threshold $\mathrm{RPM}_{\mathrm{w}}($ Revolutions per minute), the engine will start consuming fuel to sustain the engine 
speed. Without the kinetic energy in the transmission system of the vehicle to conquer the pump loss in the engine, $\mathrm{t}_{\mathrm{N}-\mathrm{I}-\mathrm{C}}$ time point that respresent the coasting with fuel-cut in $\mathrm{N}$ gear will happen earlier than $t_{D-F-C}$, which is the time point under the control strategy of the coasting with fuel-cut in D gear.

If the vehicle's gentle deceleration process is interrupted by the driver or ADAS control at $0 \sim \mathrm{t}_{\mathrm{N}-\mathrm{I}-\mathrm{C}}$, the fuel economy of the two strategies is of no difference. If it ends at $\mathrm{t}_{\mathrm{N}-\mathrm{I}-\mathrm{C}} \sim$ $t_{D-F-C}$, the fuel cut-off in D gear option will be more fuel efficient because the engine has not injected fuel, and this prevailing will be sustained also at the time points adjacent to $t_{D-F-C}$. If the deceleration ends at a time point much later than $t_{D-F-C}$, the fuel cut-off in $\mathrm{N}$ gear option is more fuel-efficient, because the overall comprehensive merit in coasting distance and the relatively lower rate of idle fuel injection will be more beneficial to the fuel reservation than the option of fuel cut-off in D gear. With ADAS/CAV, a proper choice can be made between these two options, depending on the speed of the vehicle and the traffic conditions.

OSU's Research the NCC (Neutral Coasting Control) management strategy based on ADAS / CAV technology to identify coasting opportunities ${ }^{[18]}$, and an algorithm is applied to abandon those seemingly opportunities for coasting, which is in fact is contrary. They are not coasting opportunities because the driver or ADAS will interrupt the gentle deceleration by a reacceleration or braking very soon. NCC (Neutral Coasting Control) management strategy can save $3 \%$ fuel in urban driving or suburb driving.

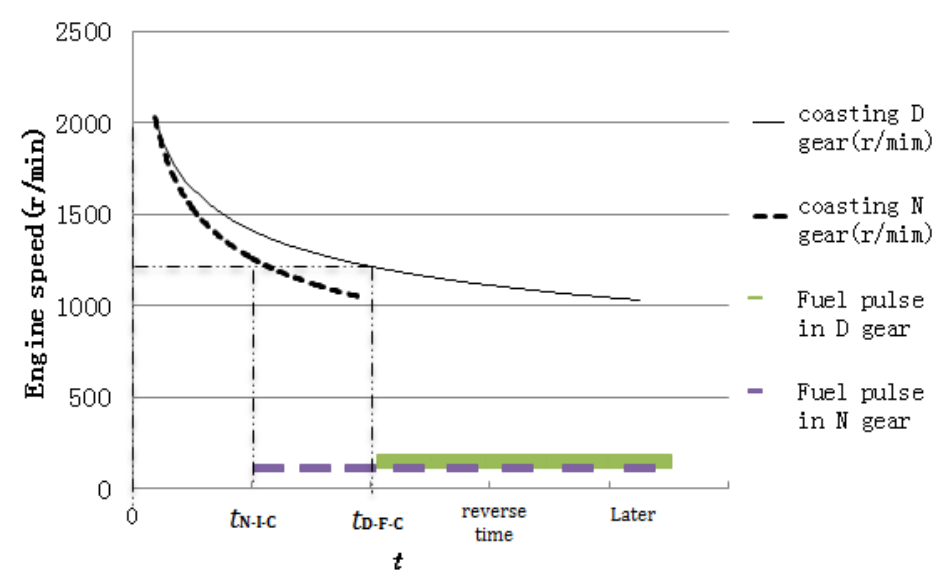

Fig. 7. the rotating speed and fuel injection during coasting control in $\mathrm{N}$ gear .vs. in $\mathrm{D}$ gear.

Furthermore, the $48 \mathrm{~V}$ technology vehicle equipped with a cold storage evaporator can further extend the coasting range under the NEDC cycle at $35^{\circ} \mathrm{C}$, so as to contribute extra $5 \%$ fuel saving ${ }^{[27]}$.

\subsection{Other relevant affairs}

Many new components necessary for ADAS / CAV are supplemented to the vehicle, which consume electricity during operation, which is can be sourcing back to the fuel. The solution to the problem of excessive power consumption is to use special integrated hardware chips for intelligent driving vehicles. 


\section{Summary}

European Union and the United States have carried out many researches to investigate the fuel conservation potential of ADAS / CAV, which can endow vehicles sensing ability and the communicating ability.

When intelligence, interconnection, and electrical control are organically coordinated, with the support of $\mathrm{V} 2 \mathrm{X}$ and $\mathrm{X} 2 \mathrm{~V}$, vehicles are more likely to be offered "convenience" by road facilities and neighboring vehicles. The fuel-saving potential also comes from a wider range of information guidance, including local big data such as slope terrain provided by interconnection, intelligent arrangement and pre-adjustment of vehicle control components and systems.

\section{References}

1. Varnhagen R."Electronic Horizon: A Map as a Sensor and Predictive Control[J]. SAE Technical Paper 2017-01-1945, 2017.doi:10.4271/2017-01-1945,P1, P34.

2. James $\mathrm{R} \quad$ Sayer Safety $\quad$ Pilot Model Deployment[J/OL].http://www.umtri.umich.edu/our-results/projects/safety-pilot-model -deployment.2014-02-16[2019-11-15]

3. UMTRI, U-M. Two National Labs to Study Energy Savings in Connected Vehicles[N/OL].http://www.umtri.umich.edu/what-were-doing/news/u-m-two-national -labs-study-energy-savings-connected-vehicles.2015-11-19[2019-11-15]

4. Jean-Charles Pandazis.eCoMove Cooperative Mobility Systems and Services for Energy Efficiency[J/OL]. http://ecomove-project.eu/assets/Uploads/Publications/eCoMoveBrochuresecured.pdf, P3-4. 2014-01-01[2019-11-15]

5. Farzaneh R, Zietsman J A, Lee D, et al. Texas-Specific Drive Cycles and Idle Emissions Rates for Using with EPA's MOVES Model - Final Report[J]. Diesel Trucks, 2014.

6. Jun Liu, Kara M.kockelman, Aqshems Nichols. Anticipating the Emissions Impacts of Smoother Driving by Connected and Autonomous Vehicles Using the MOVES Model[J/OL]. Transportation Research Board Annual Meeting, 2017. http://tti.tamu.edu/documents/0-6629-1.pdf , P4-11. 2017-01-01[2019-11-15]

7. Feng Yujiu, Zhao Wei, Qian Guogang, Evironment simulation parameters settings for the tests of LDV's AC system Performance[J], Refrigeration and Air-conditioning, 2016(5):79-86.

8. Europe Commission. L3 Pilot -Piloting Automated Driving on European Roads[N/OL]. https://cordis.europa.eu/project/rcn/210915_en.pdf, P1. 2017-0901[2019-11-15]

9. The Joint Research Center Institute for Energy and Transport. Technical Guidelines for the Preparation of Applications for the Approval of Innovative Technologies Pursuant to Regulation (EC) No 443/2009 of the European Parliament and of the Council (version Feb. 2013) [S]. P7-9.

10. Europe Commission. On the Approval of the Bosch System for Navigation-Based Preconditioning of the Battery State of Charge for Hybrid Vehicles as an Innovative Technology for Reducing CO2 
Emissions from Passenger Cars Pursuant to Regulation (EC) No 443/2009 of the European Parliament and of the Council 6 (Oct. 2013): 2013/529/EU[S]P3-5.

11. Europe Commission. On the Approval of the Engine Idle Coasting Function as an Innovative Technology for Reducing CO2 Emission from Passenger Cars Pursuant to Regulation(EC) No 443/2009 of the European Parliament and of the Council (Dec. 2018):EU 2018/2079 [S] .P3-11.

12. ARPA-E.NEXT-Generation Energy Technologies for Connected and Automated on-Road-vehicles (NEXTCAR)

Program Overview[N/OL].https://arpa-e.energy.gov/sites/default/files/documents/files/NEXTC AR_ProgramOverview.pdf, P1. 2017-01-01[2019-11-15]

13. Zhao J, Wu H,Chang CF.Virtual Traffic Simulator for Connected and Automated Vehicles[J]. SAE Technical Paper 2019-01-0676, 2019. doi: 10.4271/2019-01-0676, P1.

14. Block B, Huynh B, Boyle S, Stockar S, et al. Analysis of the Effect of Vehicle Platooning on the Optimal Control of a Heavy Duty Engine Thermal System[J]. SAE Technical Paper 2019-01-1259,2019. doi: 10.4271/2019-01-1259, P8.

15. Robinette D, Kostreva E, Krisztian A, et al. PHEV Real World Driving Cycle Energy and Fuel and Consumption Reduction Potential for Connected and Automated Vehicles[J]. SAE Technical Paper 2019-01-0307, 2019. doi: 10.4271/2019-01-0307, P12.

16. Rengerajan S B, Hotz S, Hirsch C, et al.Test Methodology to Quantify and Analyze Energy Consumption of Connected and Automated Vehicles[J]. SAE Technical Paper 2019-01-0116, 2019. doi: 10.4271/2019-01-0116, P6.

17. Olin P, Aggoune K, Tang L, et al.Reducing Fuel Consumption by Using Information from Connected and Automated Vehicle Modules to Optimize Propulsion System Control[J]. SAE Technical Paper 2019-01-1213, 2019. doi: 10.4271/2019-01-1213, P1.

18. Lee H, Lee J, Yoo S, et al.Utilization of ADAS for Improving Performance of Coasting in Neutral[J]SAE Technical Paper 2018-01-0603, 2018. doi:10.4271/2018-01-0603, P2-5.

19. Santin O, Beran J, Mikuláš O, et al.On the Robustness of Adaptive Nonlinear Model Predictive Cruise Control[J].SAE Technical Paper 2018-01-1360, 2018. doi:10.4271/2018-01-1360, P12.

20. Baker D, Asher Z D, Bradley T.V2V Communication Based Real-World Velocity Predictions for Improved HEV Fuel Economy[J].SAE Technical Paper 2018-01-1000, 2018. doi:10.4271/2018-01-1000, P7,P9.

21. Tunnell J A, Asher Z D, Pasricha S, et al.Towards Improving Vehicle Fuel Economy with ADAS[J].SAE Technical Paper 2018-01-0593, 2018. doi:10.4271/2018-01-0593.

22. Asher ZD, Tunnell J A, Baker D A, et al.Enabling Prediction for Optimal Fuel Economy Vehicle Control[J].SAE Technical Paper 2018-01-1015, 2018. doi:10.4271/2018-01-1015.

23. Tale L, Hochgrab S, Hall J, et al.Energy Efficiency of Autonomous Car Powertrain[J].SAE Technical Paper 2018-01-1092, 2018. doi: 10.4271/2018-01-1092, P8.

24. Wang Xu, Du Guangqian, Huang Yong, Research on Predicting and Tracking Algorithm of SOC Trajectory for PHEV with Traffic Information Considered[J]. Journal of Chongqing University of Technology(Natural Science), 2018(8):1-7. 
25. Kim, D., Eo, J.S., Kim, Y., Guanetti, J. et al., "Energy-Optimal Deceleration Planning System for Regenerative Braking of Electrified Vehicles with Connectivity and Automation," SAE Technical Paper 2020-01-0582, 2020, doi:10.4271/2020-01-0582, $10-12$

26. Qian Guogang, Wu Di, Qin Hongyu, Fuel Saving Effect of Cylinder Deactivation Based on Dynamic Skip Fire, Vehicle Engine, 2019(2):10-15.

27. Ozbek M, Nishida S, Biglia M,et al.Maximizing Coasting of $48 \mathrm{~V}$ Vehicles with Cold-Storage Evaporator[J]. SAE Technical Paper 2018-37-0023, 2018. doi: 10.4271/2018-37-0023, P1,P5. 